\title{
A HISTÓRIA DA QUÍMICA COMO FACILITADORA DA APRENDIZAGEM
}

\author{
Wagney William Pereira de Sousa, Universidade Federal de Campina Grande (UFCG) \\ wagney19@hotmail.com
}

Boanerges da Silva Batista, Universidade Federal do Rio Grande do Norte (UFRN)

bonzyn.fdt@gmail.com

Luciano Leal de Moraes Sales, Universidade Federal de Campina Grande (UFCG)

luciano_sales@hotmail.com

\begin{abstract}
RESUMO
Estudarhistória da Química é de suma importância para a vida de qualquer indivíduo pelo fato dessa disciplina facilitar a compreensão de conceitos e marcos da ciência. Com isso a mesma fica em evidência quando se trata de aprendizagem significativa, assumindo assima necessidade de ser incorporada ao currículo acadêmico de todo (as) os(as) Estudantes.O presente trabalho trata de uma pesquisa quantitativa e descritiva, realizada nas turmas de $2^{\circ}$ e $3^{\circ}$ ano do Ensino médio da E.E.E.F.M. Nelson Batista Alves, na cidade de Bernadino Batista no estado da Paraíba e teve como objetivo principal, analisar as contribuições que o uso da História da Química pode trazer nas aulasdo Ensino básico. Para isso foi realizada uma pesquisa bibliográfica inicial e posteriormente algumas atividades como testes de sondagem oral, aplicação de questionário e debates que buscaram compreenderas concepções dos educandos.Discutiu-se acerca de como a história da Química pode ser utilizada como mediadora no processo de Ensino e aprendizagem. Ao final do trabalho pode-se observar a busca dos educandos por aulas atrativas e dinâmicas, cabendo ao educador estimular o interesse dos mesmospor essa disciplina, podendo assim, tornar sua prática mais significativa e efetiva mesmo diante das inúmeras dificuldades enfrentadas nos dias atuais.
\end{abstract}

PALAVRAS-CHAVES: História da Química; Ensino e Aprendizagem; aprendizagem significativa.

\section{THE HISTORY OF CHEMISTRY AS A FACILITATOR OF LEARNING}

\section{ABSTRACT}

Study history of chemistry it is of the utmost importance for life of anyone because this discipline facilitate understanding of concepts and landmarks science. Thereby it's in evidence when it's about meaningful learning, assuming thus the necessity to be incorporated into the academic curriculum of students. This research is quantitative descriptive analysis performed in the 2nd and 3rd year of high school E.E.E.F.M Nelson Batista Alves, In the city of Bernardino Batista, in the state of Paraíba and had as main objective analyze the contributions the use History of Chemistry can bring in the classes of basic education. For this a literature search was conducted and later some activities such as oral probing tests, questionnaire application and discussions to tried to 
understand the students conceptions. It was discussed about how the history of chemistry can be used as a mediator in process of teaching and learning. At the end of the work, students can be observed for attractive and dynamic classes, and it is up to the educator to stimulate their interest in this discipline, so that they can make their practice more meaningful and effective even in the face of the many difficulties they face today.

KEYWORDS: History of Chemistry; Teaching and Learning; Meaningful Learning

\section{LA HISTORIA DE LA QUÍMICA COMO FACILITADORA DEL APRENDIZAJE RESUMEN}

EstudiarHistoria de la Química es de suma importancia para la vida de cualquierindividuo por elhecho de que esta disciplina facilitar lacomprensión de conceptos y marcos de laciencia. Conellolamisma queda en evidencia cuando se trata de aprendizaje significativo, asumiendoasílanecesidad de ser incorporada al currículo académico de todos losestudiantes. El presente trabajo trata de una investigacióncuantitativa y descriptiva, realizada enlasclases de $2^{\circ}$ y $3^{\circ}$ año de laEnseñanza media de E.E.E.F.M. Nelson Batista Alves, enlaciudad de Bernadino Batista enel estado de Paraíba y tuvo como objetivo principal, analizarlascontribuciones que el uso de laHistoria de la Química puedetraerenlasclases de laEnseñanza básica. Para ello se realizó una investigación bibliográfica inicial y posteriormente algunasactividades como pruebas de sondeo oral, aplicación de cuestionario y debates que buscaroncomprenderlasconcepciones de los educandos. Se discutió acerca de cómolaHistoria de la Química puede ser utilizada como mediadora enelproceso de Enseñanza y aprendizaje. Al final deltrabajo se puede observar labúsqueda de los educandos por clasesatractivas y dinámicas, cabiendo al educador estimular elinterés de losmismos por esa disciplina, pudiendoasí, hacersupráctica más significativa y efectiva incluso ante lasinnumerablesdificultades enfrentadas enlosdíasactuales.

Palabras claves: Historiade la química; Enseñanza y Aprendizaje; Aprendizaje significativo.

\section{INTRODUÇÃO}

Como se sabe a Química é uma ciência, e com isso sua base conceitual busca compreender melhor os fenômenos que ocorrem na natureza. Para que essa ciência seja compreendida e transmitida para os demais indivíduos da sociedade são necessários profissionais da educação que estejam preparados para enfrentar problemáticas que impeçam ou dificultem tal disseminação de conceitos.

Atualmente é reconhecido bastante o grau de importância que a História da Química tem para a formação educacional e social de todos(as) os(os) Estudantes. Isso por sua vez resulta em uma preocupação maior na pesquisa sobre essa 
perspectivametodológica, e com isso tentativas de inserção desta tendência alternativade ensinosão desenvolvidos para que se possa inserir vida acadêmica de cada envolvido no processo de construção cognitivo do conhecimento elaborado. Tal afirmação pode ser confirmada nas seguintes palavras:

Como consequência, vêm acontecendo ações oficiais e não oficiais no sentido de buscar inserir a História da Ciência nos currículos que têm emergido de reestruturações curriculares mais recentes. No Brasil, de alguma forma esta tendência aparece explicitada em documentos oficiais, como os Parâmetros Curriculares Nacionais para o Ensino Médio (PCNs) e as Novas Diretrizes Curriculares para os cursos de graduação. (OKI E MORADILLO, 2008, P.68).

Entre os maiores problema enfrentados hoje, em sala de aula, merece destaque a dificuldade de contextualizar dos conhecimentos essenciais à disciplina de Química no dia-a-dia dos educandos pelos seus respectivos educadores. Pensando nestas questões, entende-se que o ensino deve proporcionar a qualquer indivíduo uma autonomia na construção da identidade cidadã bem como sua capacidade de serem críticos e participativos diante de situações-problemas cotidianas.

Nesse sentido, os alunos do Ensino Médio necessitam de uma proposta para uma abordagem ordenadae sobre tudo condizente com os fatos da História da Química para que assim se possa confrontá-la com o contexto vivenciado pelos educando, sempre buscando Partir da realidade sociocultural e econômica existente, deixando que os envolvidos do vejam a importância do conhecimento cientifico para a humanidade, e com isto, entendimento a importância da História da Química para construção de uma base de aprendizagem solida e moldada nos princípios educacionais atuais. 


\section{METODOLOGIA}

O referido projeto buscou analisara realidade das aulas de Química da E.E.E.F.M. Nelson Batista Alves, bem como o uso do contexto histórico de cada conteúdo de Químicacom uma metodologia que facilite a aprendizagem. E teve como público alvo os alunos do $2^{\circ}$ e $3^{\circ}$ Ano do Ensino Médio Regular, da referida, escola pública que faz parte da rede estadual de ensinodo estado da Paraíba.

O método aplicado no desenvolvimento do mencionado projeto teve como ponto inicialuma pesquisa bibliográfica muito abrangente sobre o tema:O uso da História da Química nas aulas, bem como alguns temas transversais como: Cidadania e ética que estão relacionados com a prática docente. Diante da pesquisa, as concepções e metodologias que serviram de base foram deBachelard (1996), Giassi e Moraes (2010), Chaves (2014) e Viana (2011). Tais ideias servem como ponto de referência para aplicação de uma vertente sobre algumas concepções alternativas em relação à prática de ensino e a relação ensino-aprendizagem.

Inicialmente foi traçado um perfil das turmas através de alguns testes de sondagens realizados oralmente. Como mostra a Tabela 1:

Tabela 1 - Mostra as perguntas realizadas na pesquisa sobre o tema

\begin{tabular}{|l|l|}
\hline Pergunta 1 & $\begin{array}{l}\text { Você considera as aulas de Química, } \\
\text { divertidas } \\
\text { ou monótonas? Justifique. }\end{array}$ \\
\hline Pergunta 2 & $\begin{array}{l}\text { Você considera importante estudar a Historia } \\
\text { da Química? Justifique. }\end{array}$ \\
\hline Pergunta 3 & $\begin{array}{l}\text { Como você acha que as aulas de } \\
\text { Química ficariam mais proveitosas? }\end{array}$ \\
\hline Pergunta 4 & $\begin{array}{l}\text { Você conhece algum marco histórico } \\
\text { Relacionado a Química? Diga qual. }\end{array}$ \\
\hline
\end{tabular}

Fonte: Acervo do autor

O perfil do professor da disciplina de Química também foi traçado através de uma entrevista sobre sua formação, sobre sua prática e sua visão em relação à história da Química como norteadora da aprendizagem significativa. 
Posteriormente para dar início a coleta de dados foi proposta um questionário para os educandos com perguntas abertas que buscavam entender as concepções dos mesmos em relação a História da Química e a importância de se entender tais conceitos históricos antes de assimilar qualquer conteúdo programático e abstrato, já que segundo de Beltran (2013, P.69) "Pesquisadores em ensino de química vêm manifestando de forma cada vez mais intensaa valorização da história da ciência como importante componente na formação tanto dos estudantes quanto dos professores."

De fato, quanto mais cedo for inserido a historicidade que envolve os fato relacionados as descobertas cientificas, em particular da disciplina Química, maior será o entendimento do discente pelo determinado assunto, seja no Ensino básico, seja no Ensino superior. A entrevista com o professor foi mais voltada para a sua prática, e a importância da História daQuímica para o Ensino e aprendizagem na formação indivíduos capazes de uma vida em sociedade de forma cidadãos crítica e participativa.

O tratamento dos dados e levantamentos de estatísticosfoi feito e representado em forma de gráficos nos quais constaram a opinião dos discentes e seus anseios sobre o tema em questão bem como suas perspectivas de aprendizagem, por sua vez os dados do professor foram discutidos em forma de texto dissertativo, levantando uma breve discussão sobre prática pedagógica.

\section{RESULTADO E DISCUSSÃO}

Enfatizou-se o conhecimento prévio que os educandos tinham sobre os entendimentos mais relevantes sobre a disciplina de Química bem como a utilização da história para facilitar o ensino-aprendizagem na referida área. Os dados obtidos foram bastante esclarecedores acerca dos anseios dos mesmos em relação de como eles gostariam que fossem as aulas de Química e da facilidade que a compreensão dos conteúdos estudados poderiam ser melhorados com o uso de metodologias inovadoras entre elas a História da Química.

Inicialmente perguntou-se qual a opinião deles a respeito das aulas de Química, ou seja, se eram atrativas e divertidas, ou monótonas. O resultado foi que grande parte dos educandos consideraram tais aulas como monótonas, apresentando a justificativa de que não tinham experimentos e que os conteúdos eram muito difíceis, uma quantidade 
intermediaria deles responderam que as aulas eram divertidas e interessantes, pois eram abordadas de forma simples. Grande parte preferiu não opinar e alguns por sua vez preferiram não justificar o porquê consideram as aulas monótonas. Como mostra o gráfico 1 representado a seguir:

Gráfico 1- Opinião dos educandos a respeito das aulas de Química

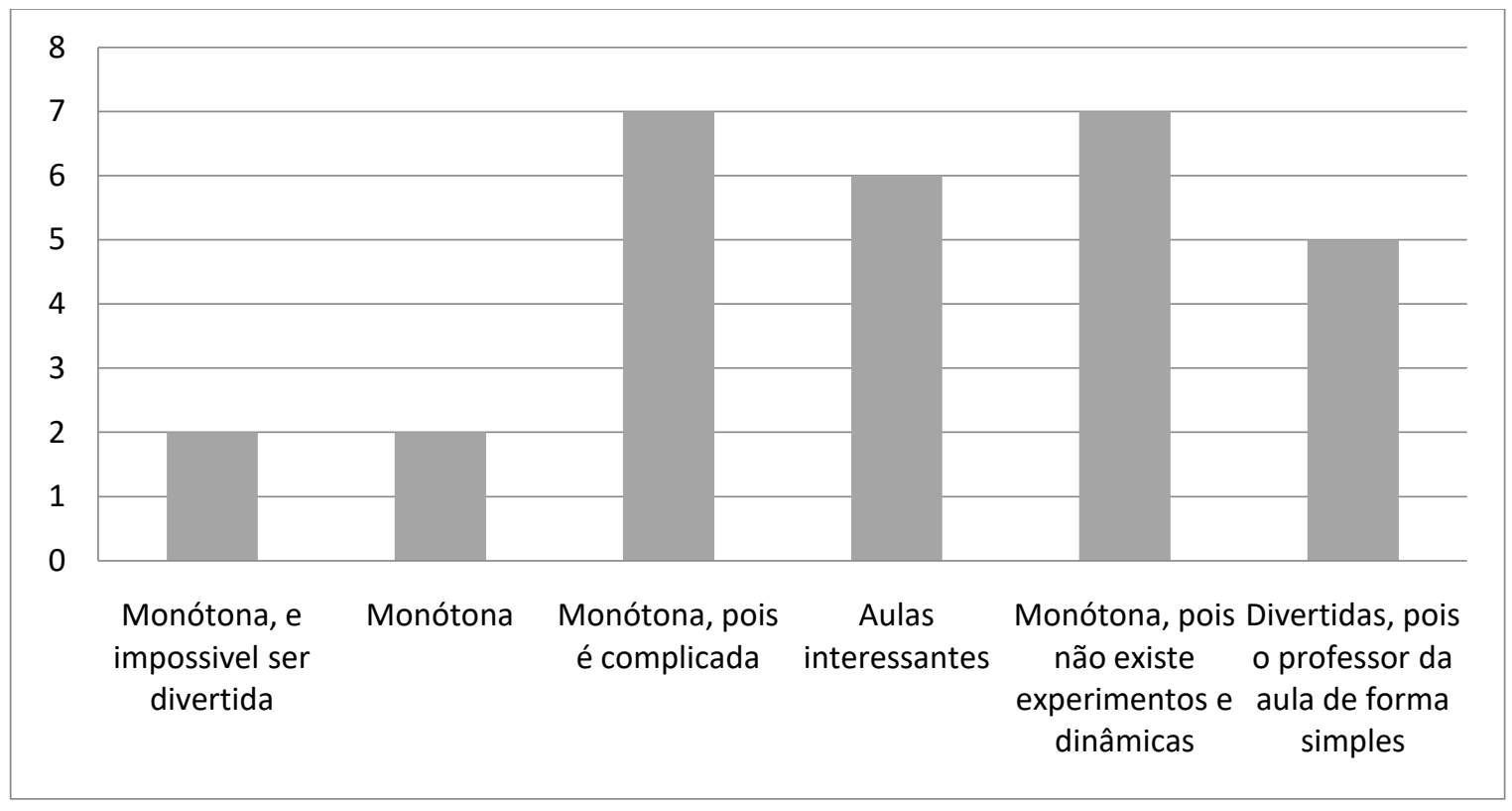

Fonte: Acervo do autor

Nessa perspectiva pode-se entender que os educandos demonstraram um certo descontentamento com as aulas, fato esse que evidencia a necessidade de se realizar um melhor planejamento por parte do educador, bem como uma auto avaliação, para que o mesmo possa rever sua metodologia e possa tomar providencias.

Em seguida, a problemática levantada foi a importância da história da Química para a vida dos educandos. A resposta unânime foi que estudar história da Química é sim de fato importante por vários motivos tais como: facilita o aprendizado e pelo fato de ser interessante com mostra o gráfico 2 representado a diante: 
Gráfico 2 - Concepção dos educandos sobre a importância de estudar história da Química.

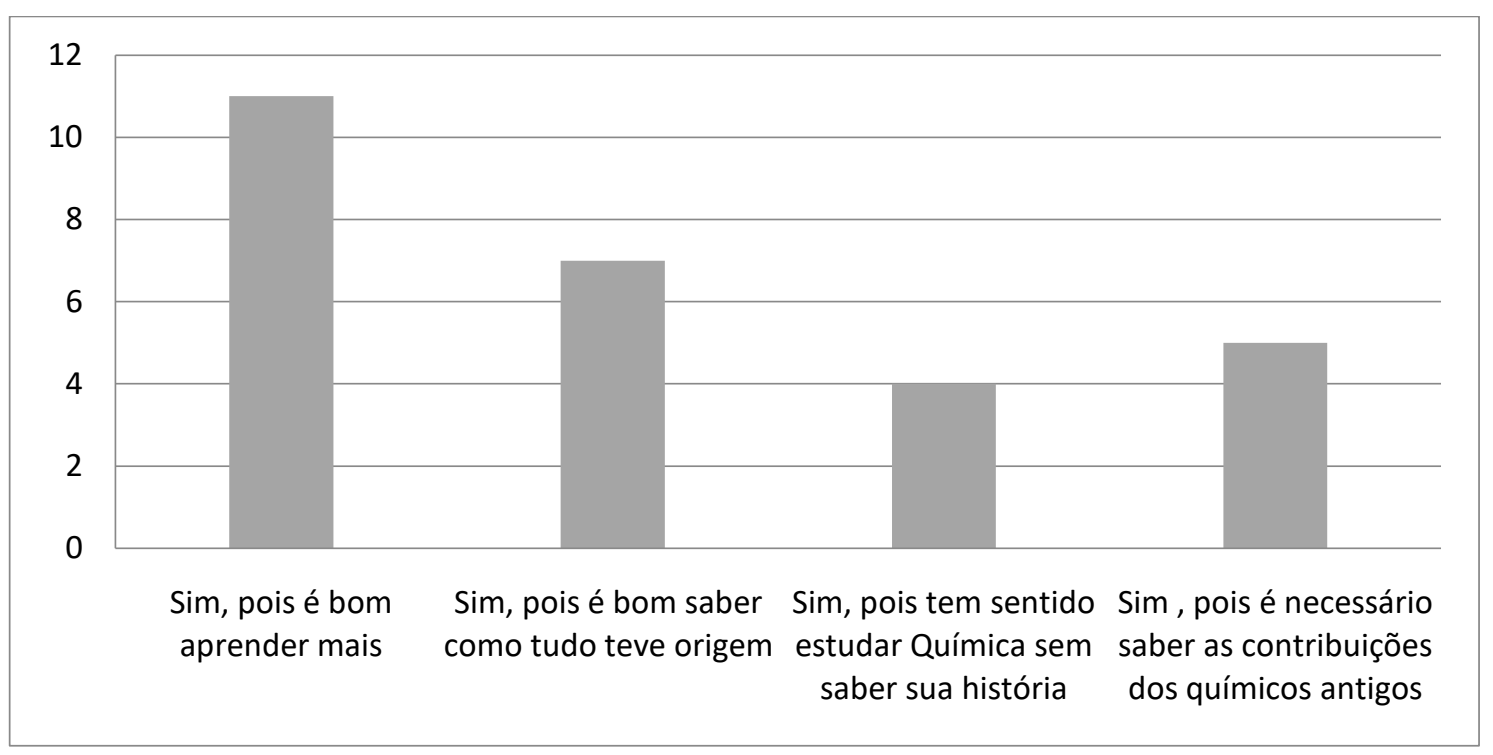

Fonte: Acervo do autor

De fato, todo e qualquer indivíduo tem consciência do grau de importância que tem a aprendizagem de conceitos históricos e até mesmos básicos da ciência, pois sem entender tais conceitos o mesmo sentirá dificuldade para se situar na atual sociedade que por sua vez está em constante desenvolvimento. Essa afirmação pode ser melhor evidenciada nas palavras de Paixão e Figueiredo (2015, p.295):

[...] torna-se imprescindível que todos os cidadãos tenham acesso a conhecimentos básicos sobre Ciência e Tecnologia de modo a intervirem de forma ativa na Sociedade. Do mesmo modo que se aceita como fundamental que todos oscidadãos necessitam de um nível adequado de literacia relativa ao uso da língua e da matemática, as exigências atuais da vida em sociedade tornam também indispensável que seja facultada, a todos os cidadãos, formação científica e tecnológica identificada com literacia neste domínio.

Outra questão abordada foram as concepções dos alunos sobre como ficariam mais proveitosas as aulas de Química. Uma grande maioria respondeu que aprenderiam mais durante as aulas, se o professor realizasse experimentos ou algum tipo de prática demonstrativa sobre o conteúdo abordado. Os demais responderam que as aulas necessitam de mais diálogo e interação com o professor, mencionaram também aulas de campo e oficinas. Uma minoria respondeu que as aulas já são divertidas, que não mudariam nada e que deveria ter menos cálculos e mais teorias para que por sua vez não 
virassem monótonas e dificultassem a aprendizagem dos conteúdos abordados. Tais resultados foram expressos no gráfico 3 representado a seguir.

Figura 3: Opinião dos educandos sobre como deveriam ser as aulas de Química.

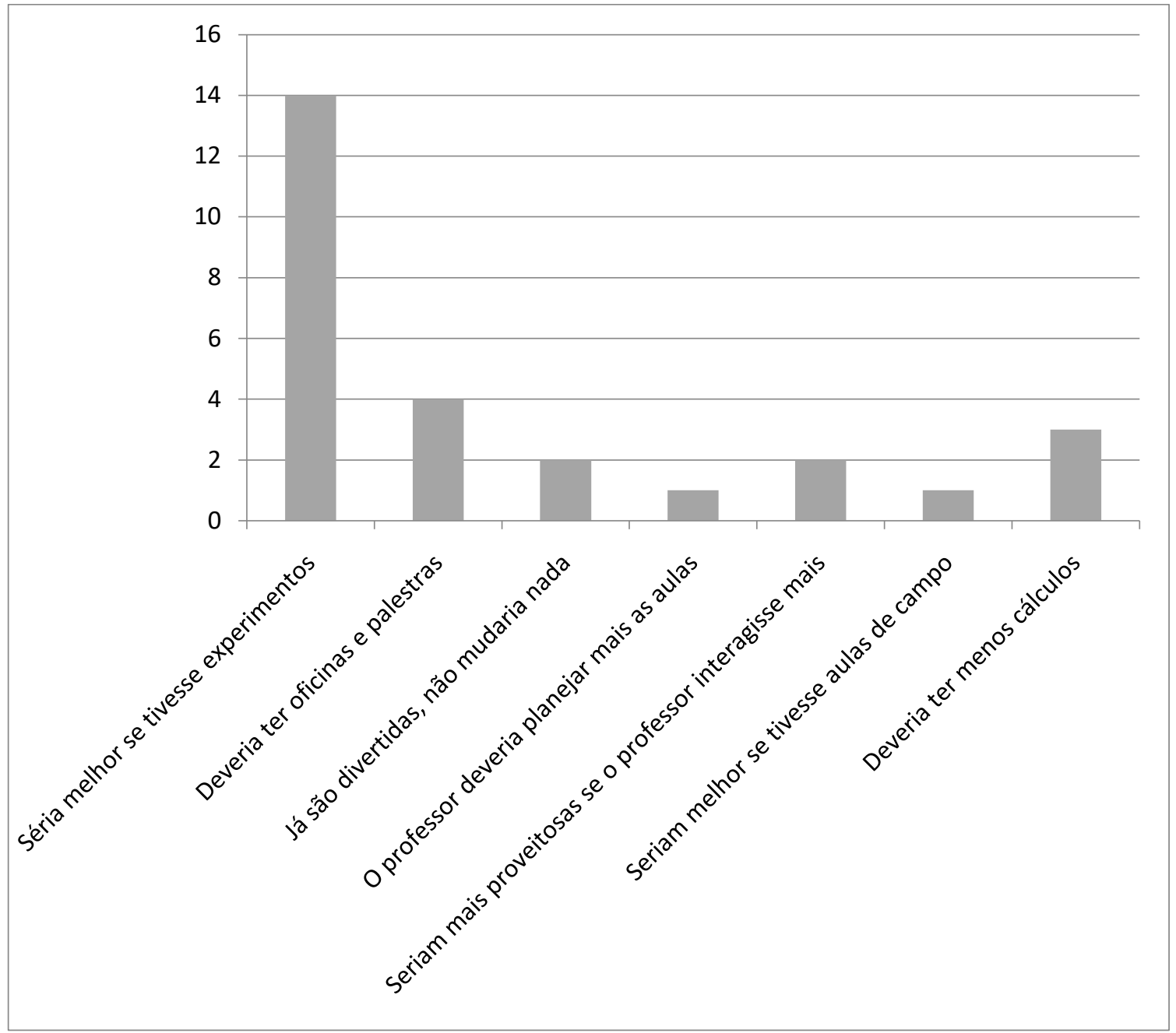

Fonte: Acervo do autor

E por fim foi perguntado se os educandos conheciam algum marco ou acontecimento histórico relacionado a Química. Como mostra o gráfico4, uma maioria esmagadora respondeu negativamente. Alguns alunos ainda responderam que conhecem fatos como a história do anel benzênico, o uso de drogas durante a segunda guerra mundial, a história do átomo e descoberta do urânio e até mesmo a contaminação com Césio no acidente em Goiânia. 
Gráfico 4 - Relação de marcos relacionados a história da Química que os educandos conhecem.

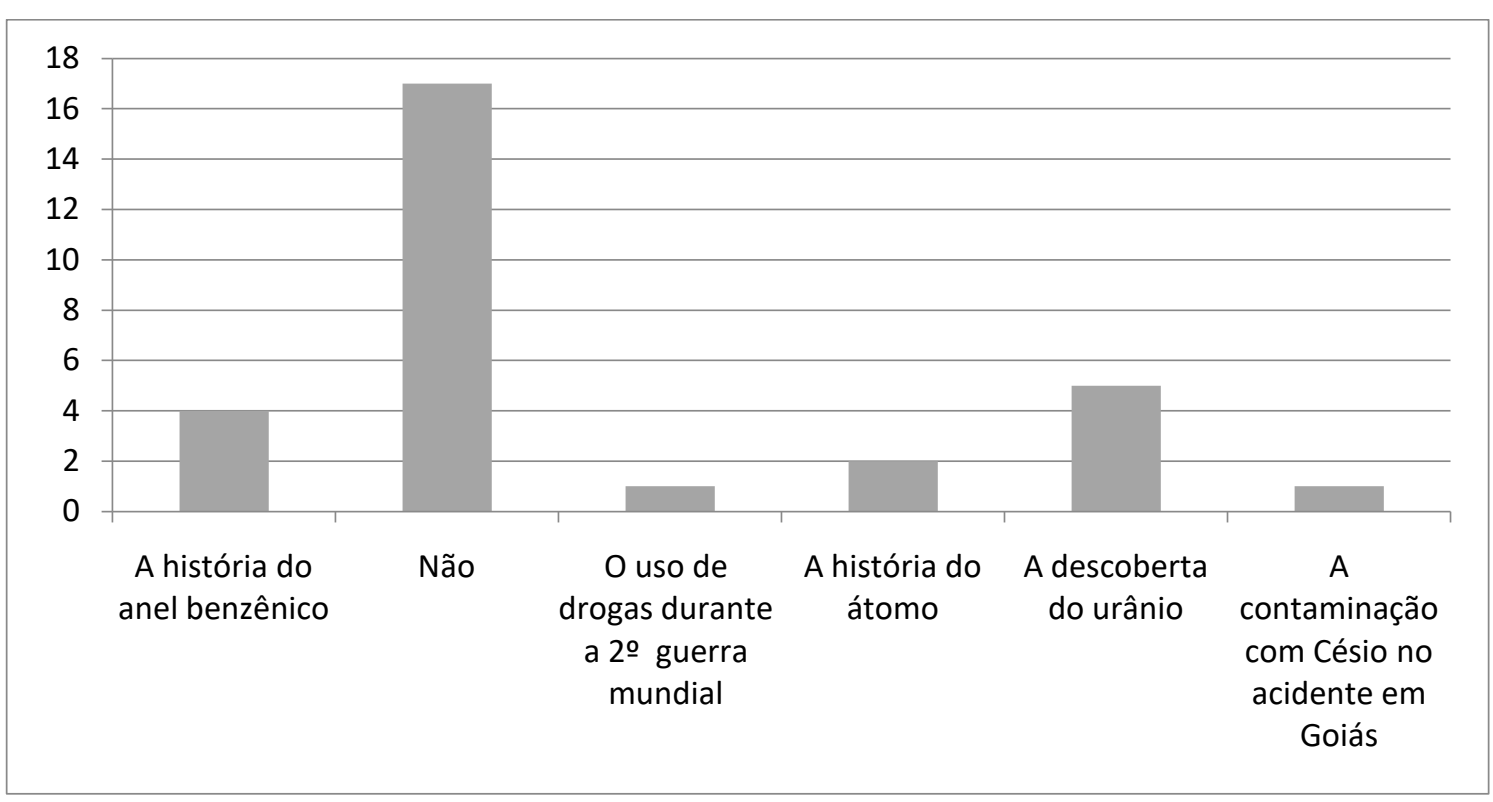

Fonte: Acervo do autor

Dentre os resultados analisados na pesquisa, pode-se verificar no gráfico 4 que grande maioria dos educandos da referida escola almejam uma melhoria nas aulas de Química e que esperam do educador uma melhor interação nas aulas, bem como aulasexperimentais que atraiam a atenção de ambos. Em relação a necessidade de realizar experimentos deve-se levar em consideração o fato da escola não ter aparatos e materiais essenciais para utilização do professor em laboratório, mas que tal fato não é um impedimento da realização dessa atividade, pois cabe ao educador em questão planejar metodologias alternativas para lidar com as imposições e problemas que surgirão em sua prática pedagógica durante sua vida profissional, ou seja, cabe a ele planejar experimentos com materiais alternativos e de fácil acesso para os educandos, para que assim aconteça uma melhoria na sua prática pedagógica. Porém sabe-se que antes dessas aulas experimentais serem realizadas, o educador deve fazer todo um embasamento histórico sobre o conteúdo estudado e não penas expor o que já está no livro didático. Nesse sentido pode-se mencionar as palavras de Chaves, Santos e Carneiro (2014, p.278):

Entende-se que a melhoria da qualidade do ensino de química inclui uma contextualização histórica, oportunizando meios para uma reflexão crítica dos conteúdos abordados. Assim, é preciso que os professores de química entendam que ensinar conceitos científicos de química exige introduzir não apenas os trechos históricos 
fragmentados da HC, como apresentados nos LD, mas, sobretudo, as relações de produção do conhecimento científico em contexto mais amplo das sociedades.

De fato uma aprendizagem significativa sobre a História de conceitos da Ciência não deve ser restrita somente ao que está exposto nos livros didáticos, nem ao menos a meras arguições orais nas aulas. Ao contrário disso, o educador por sua vez, deve estimular as características desbravadoras dos jovens, usufruindo de marcos sociais que ficaram registrados na história da civilização humana.

\section{CONCLUSÃO}

O grande desafio de um educador na sala de aula é promover uma aula diferenciada e que estimule os educandos, bemcomo formar cidadãos conscientes de seu papel diante da sociedade em que vivemos. Diante da referida pesquisa, foi concluído que atualmente os educandos buscam aulas que são atrativas e que possam lhes trazer uma melhor compreensão do conteúdo estudado. Daí nasce a necessidade de se estudar história da Química, cabendo ao educador estimular tal interesse dos seus aprendizes em relação a essa disciplina que por muitas vezes é considerada difícil e incompreensiva.

Com os dados obtidos e representados anteriormente ficou expresso de forma clara que os educadores da área de Química devem buscar meios e metodologias que estimulem a aprendizagem,o uso da História da Química foi uma dessas metodologias sugeridas e que podem tornar sua prática mais significativa e efetiva mesmo diante das inúmeras dificuldades enfrentadas nos dias atuais. Porém para isso, o mesmo deve-se se reciclar e aperfeiçoar sua prática pedagógica para que ele se atualize de acordo com as necessidades exigidas com os avanços da sociedade moderna que já vieram ou estão por vir.

Ficou expressa a necessidade dos educandos de estudarem mais sobre a história da Química, que como já mencionada é de extrema importância para a assimilação de qualquer conteúdo da área. Com isso surge a questão da metodologia do docente que deverá sempre buscar rever sua prática pedagógica e por sua vez procurar fazer a relação da teoria e prática com conceitos históricos relevantes a vida dos educandos em questão, buscando assim uma aprendizagem significativa, fugindo desse paradigma de ensino tradicional de ensino. 


\section{REFERÊNCIAS}

BELTRAN M.H.R. História da Química e Ensino: Estabelecendo interfaces entre campos interdisciplinares.Abakós, Belo Horizonte, V.1, n.2, p.67-77, maio 2013.

CHAVES, L. M. M. P.; SANTOS, W.L.P.; CARNEIRO, M.H.S. História da ciência no estudo de modelos atômicos em livros didáticos de Química e concepções das ciências.Química nova na escola, São Paulo-SP, vol.36, n.4, p.269-279, novembro 2014.

OKI M. C. M.; MORADILLO D. F. O ensino de História da Química: contribuindo para a compreensão da natureza da ciência. Ciência e Educação. Vol. 14, n.1, p.6788, 2008.

PAIXÃO F.; FIGUEIREDO M. História da Química na sala de aula para ensinar sobre a natureza da ciência: o exemplo da interdependência entre ciência $e$ tecnologia. Interações, N.34,p. 292-311, 2015. http://www.eses.pt/interações/ acesso em: 03/08/2016 às 20:28. 